\title{
Foliar Sprays of Citric Acid and Malic Acid Modify Growth, Flowering, and Root to Shoot Ratio of Gazania (Gazania rigens L.): A Comparative Analysis by ANOVA and Structural Equations Modeling
}

\author{
Majid Talebi, ${ }^{1}$ Ebrahim Hadavi, ${ }^{2}$ and Nima Jaafari ${ }^{1}$ \\ ${ }^{1}$ Graduate School of Horticulture, Islamic Azad University, Karaj Branch, Karaj 31876 44511, Iran
}

${ }^{2}$ Department of Horticulture, Islamic Azad University, Karaj Branch, Karaj 31876 44511, Iran

Correspondence should be addressed to Ebrahim Hadavi; hadavi@kiau.ac.ir

Received 30 April 2014; Accepted 11 September 2014; Published 28 October 2014

Academic Editor: Pia Parolin

Copyright (C) 2014 Majid Talebi et al. This is an open access article distributed under the Creative Commons Attribution License, which permits unrestricted use, distribution, and reproduction in any medium, provided the original work is properly cited.

\begin{abstract}
Foliar application of two levels of citric acid and malic acid (100 or $300 \mathrm{mg} \mathrm{L}^{-1}$ ) was investigated on flower stem height, plant height, flower performance and yield indices (fresh yield, dry yield and root to shoot ratio) of Gazania. Distilled water was applied as control treatment. Multivariate analysis revealed that while the experimental treatments had no significant effect on fresh weight and the flower count, the plant dry weight was significantly increased by $300 \mathrm{mg} \mathrm{L}^{-1}$ malic acid. Citric acid at 100 and $300 \mathrm{mg} \mathrm{L}^{-1}$ and $300 \mathrm{mg} \mathrm{L}^{-1}$ malic acid increased the root fresh weight significantly. Both the plant height and peduncle length were significantly increased in all applied levels of citric acid and malic acid. The display time of flowers on the plant increased in all treatments compared to control treatment. The root to shoot ratio was increased significantly in $300 \mathrm{mg} \mathrm{L}^{-1}$ citric acid compared to all other treatments. These findings confirm earlier reports that citric acid and malic acid as environmentally sound chemicals are effective on various aspects of growth and development of crops. Structural equations modeling is used in parallel to ANOVA to conclude the factor effects and the possible path of effects.
\end{abstract}

\section{Introduction}

Gazania is a small genus of 16 species, all endemic to southern Africa belonging to the Asteraceae (Compositae) family. It is a member of the tribe Arctoteae, subtribe Gorteriinae, which includes seven other genera: Berkheya, Gorteria, Cuspidia, Didelta, Heterorhachis, Cullumia, and Hirpicium [1]. Besides other flower species, the Gazania rigens L., a member of annual flowers, represents an important decorative material for public greens, gardens, flower stands, and so forth [2]. It is propagated easily and has attractive flowers with a long flowering period, from middle spring to autumn; Gazania is used extensively in urban decorations nowadays. However, Gazania is considered among those landscape groundcovers that are susceptible to water stress [3]. Increasing of ornamental performance is a major concern, especially in harsh urban condition, which demands an increased tolerance to a variety of environmental stresses. Therefore, easy-to-apply practices that can improve the plant performance would be of interest.

Endogenous organic acids are the source of both carbon skeleton and energy for cells and are used in the respiratory cycle and other biochemical pathways. Therefore, they can influence the cut flower's vase life [4]. Malic acid is metabolized in plant mitochondria by reaction of malic enzyme [5]. Malate is a common reserve anion playing a role in the plant vacuole as counter ion for $\mathrm{K}$ and $\mathrm{Ca}$ [6], especially in nitrate-dependent plants [7]. Roots of calcicole plants (plants growing in alkaline soils) exudate citrate and malate, which enables them to extract $\mathrm{P}$ and Fe from such soils [8]. Eidyan et al. reported that citric acid spray $(0.1 \%, w / v)$ increased the vase life of cut tuberose plants and increased the size of bulblets in a synergism with foliar Fe [9]. Preharvest spray of citric acid $(0.15 \%, w / v)$ increased the mean vase life of cut lilium flowers from 11.8 in control treatment to 14 days 
[10]. Basil plants (Ocimum basilicum L.) treated with citric acid $(0.1 \%, w / v)$ produced higher biomass and essential oil yield [11]. In another study on dill, it was revealed that plant vegetative parameters as well as tolerance to powdery mildew were improved by the combination of $0.3 \%$ citric acid and $0.1 \%$ malic acid [12]. They suggested elevated exudation of organic acids by roots in response to foliar organic acids, which was confirmed recently by An et al. [13]. ElTohamy et al. reported that citric acid spray induced drought tolerance in bean [14]. Increased yield caused by positive interactions between citric acid spray and seed inoculation with mycorrhiza, Azotobacter, and Azospirillum is reported [15].

The present study aimed to evaluate the use of citric acid and malic acid as biostimulants for increasing the ornamental performance of Gazania. In this study, we aimed to test whether applying foliar sprays of citric acid and malic acid could increase quality and performance of an ornamental landscape decorative plant. We investigated the effect of these organic acids on both canopy and root system to check the possible change in allocation pattern between shoot and root.

\section{Materials and Methods}

The experiment was conducted in the experimental greenhouse of Qom Municipal (Qom, Iran). Citric acid and malic acid (Sigma-Aldrich, 99\% Pure) were applied as foliar sprays each at two concentrations $\left(100\right.$ or $\left.300 \mathrm{mg} \mathrm{L}^{-1}\right)$. The control treatment consisted of foliar sprays of distilled water. The experiment was conducted in a completely randomized design. Sample size was 18 pots per treatment, except for the control treatment where 9 pots were used.

Gazania seeds were planted in plugs in Nov. and then after 30 days were transplanted to plastic pots containing a (1:1:1 by volume) mixture of garden soil, leaf compost, and peat moss. The $\mathrm{pH}$ was determined $(\mathrm{pH} \approx 7)$ on a $1: 1$ medium/water mixture with a Jenway $\mathrm{pH}$ meter model 3030 (Felsted, UK). Plants were placed in a greenhouse at a mean day/night temperature of $26 / 18^{\circ} \mathrm{C}$ and a soil moisture of 60 $70 \%$. A total of six sprays were applied starting from 45 days after emergence of seeds when the leaves were about seven $\mathrm{cm}$ long. The sprays were repeated biweekly. A hand-held sprayer was used and each spraying was continued until the liquid runs off freely from the foliage. A commercial adjuvant was added to all sprays (Citogate). After the onset of flowering, the flower display time was recorded in all treatments. Other traits were recorded 150 days after emergence including the flower peduncle length, plant height, flower performance, and yield indices, including fresh yield, dry yield, and R:S (root to shoot ratio).

2.1. Data Analysis. Analysis of variance was performed by SPSS software (ver. 16.0, SPSS Inc., Chicago, USA). Preliminary analyses (examination of normal probability plots and scatterplots) were performed to insure no violation of assumptions of normality and homoscedasticity. Means were separated by Duncan's test when the $F$ test proved significant at $\alpha<0.05$. Structural equations modeling (SEM) analysis was carried out using AMOS extension of SPSS.

\section{Results}

Shoot Parameters. Plants treated with $300 \mathrm{mg} \mathrm{L}^{-1}$ malic acid produced the highest level of shoot dry weight per pot, in comparison with control (Table 1). The same pattern was noticeable in total dry biomass production by plants. However, the effect on the shoot fresh weight was less prominent, and no significant difference was noticed between treatments. Water content of Gazania plants was slightly decreased by malic acid when compared to citric acid containing treatments; however, none was considered significantly different compared to control treatment (Table 1).

Root Parameters. Both citric acid treatments and $300 \mathrm{mg} \mathrm{L}^{-1}$ malic acid increased the root fresh weight significantly (Table 1). By an increase in concentration of both applied organic acids a larger root dry weight resulted (Table 1). However, there was no difference between 100 and $300 \mathrm{mg} \mathrm{L}^{-1}$ malic acid concentrations, while in citric acid treatment, the root fresh weight was significantly larger when the concentration increased from 100 to $300 \mathrm{mg} \mathrm{L}^{-1}$. Malic acid in $300 \mathrm{mg} \mathrm{L}^{-1}$ level and both citric acid levels increased the $\mathrm{R}: \mathrm{S}$ ratio compared to control.

Flowering Parameters. All concentration of organic acids significantly lengthened the flower display time. Among treatments, only $100 \mathrm{mg} \mathrm{L}^{-1}$ of citric acid increased it significantly (Table 1). All applied levels of organic acids created significantly taller plants (Table 1). In all treatments of organic acids, Gazania plants had significantly longer peduncle than untreated control. Any significant difference among the applied concentrations of organic acids was missing (Table 1).

As it could be seen in the developed path diagram from experimental data, citric acid is nominated as the only responsible factor for increased flower display time; however, a small portion of variance is explained (7\%), and the related mechanism remains unclear (Figure 1). SEM suggests that citric acid primarily increased the plant height and, consequently, the peduncle length. In the case of malic acid, the effect on peduncle length was considered direct, while the effect on plant height is suggested to be mediated indirectly. The positive effect of malic acid on peduncle length is concurrent with a negative effect on the flower count. The observed effect on root allocation is mediated via the increase in shoot dry weight induced by both citric acid and malic acid (52\% of variance explained).

\section{Discussion}

Our results reveal a positive effect by applied organic acids on root parameters, plant height, and flowering parameters. This indicates that these organic acids could improve the ornamental value of Gazania as an outdoor decorative plant. A shift in allocation pattern of assimilates was noted as suggested before. The increase in flower display time in our experiment could be considered relatively similar with the previous findings of increased vase life by citric acid sprays reported on cut tuberose [9], lilium [10], and increased shelf 


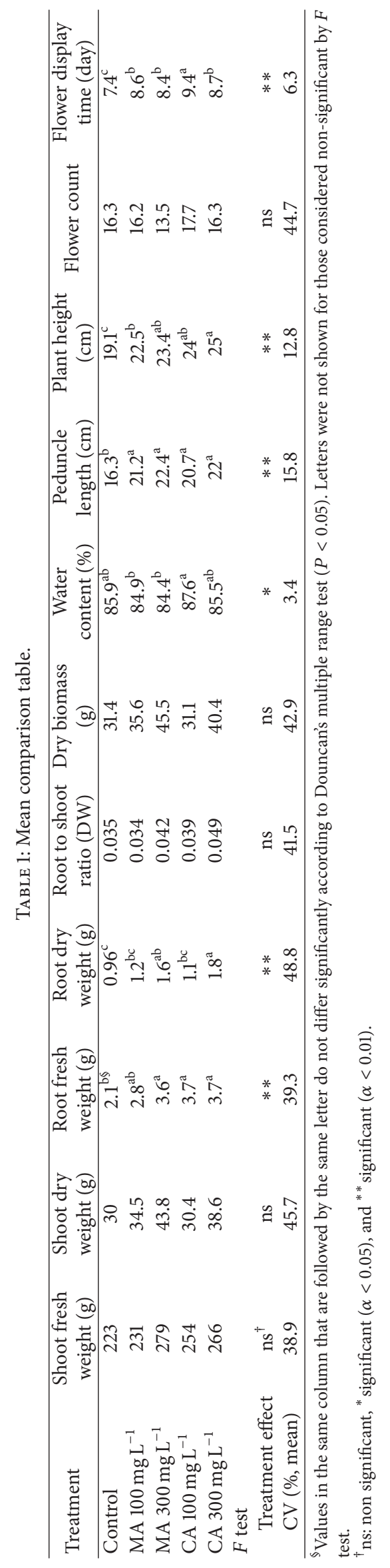




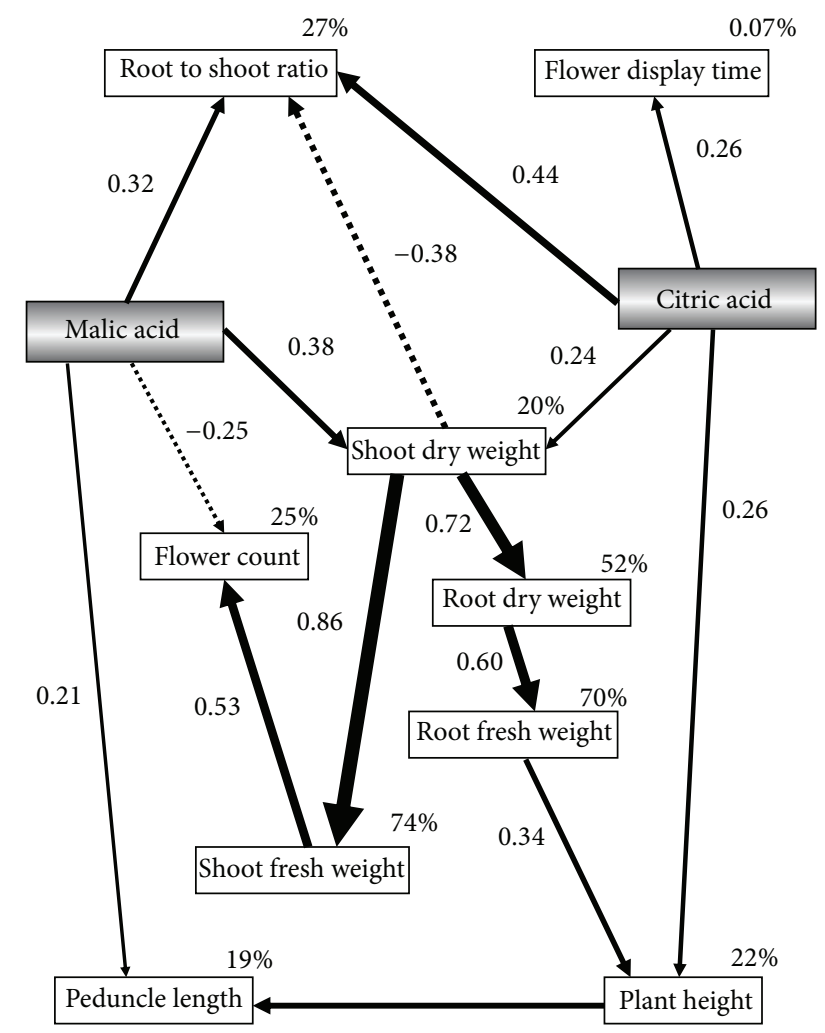

FIGURE 1: The path analysis of experimental data. Dashed lines indicate negative coefficients, and the width of the arrow indicates the strength of the effect. The lines represent significant effect and the numbers on arrows are standardized regression coefficients (when factor goes up or down by 1 standard deviation, the variable goes up or down by the multiplying the mentioned number in its standard deviation). The numbers on the upper corner of each variable are determination coefficient $\left(\mathrm{R}^{2}\right)$ (e.g., it is estimated that the predictors of the root dry weight explain 52 percent of its variance). Variation due to error is not included for simplicity.

life of fresh cut dill [12]. However, here we are reporting for the first time that both organic acids increased the lifespan of attached flowers to the plant.

The taller plants in response to spray of both organic acids are consistent with an earlier report on dill [12], where it is observed that both organic acids and their combination created taller dill plants. SEM analysis suggests that increased peduncle length is at least partially regulated by the same factors that cause increased plant height.

Eidyan et al. [9] noted a synergism between foliar application of Fe and citric acid in increasing of bulblet size in tuberose. A reduction in aerial bulbil weight by citric acid and some combinations of citric acid and malic acid sprays in lilium was reported. They suggested that this could be due to a carbohydrate partitioning effect by these organic acids [10]. Our observation of increased carbohydrate allocation to roots is in consistency with these reports. We can postulate that in those experiments a similar pattern of allocation to root system, like what we noticed here, existed that was responsible for larger underground bulblets in tuberose and reduced aerial bulbil weights in lilium.
Andrews considered Leaf $\mathrm{N}$ level [16] and leaf protein concentration [17] as factors that explain the major proportion of the variation in $S: R$ (shoot to root) ratio. Later, he concluded that all environmental influences on $S: R$ are often related mechanistically to their effects on leaf protein concentration [18]. However, while these conclusions may be applied to well fertilized plants, there are other insights to R: S ratio from the stress management viewpoint. The absolute amounts of below- and above-ground environmental stress, by the below/above-ground environmental stress ratio, and the growth potential of the species itself are suggested to determine R:S ratio [19]. In another study seedling survival of the different species was positively correlated with root allocation [20]. In our experiment, we may consider increasing $\mathrm{R}$ : $\mathrm{S}$ ratio by applied organic acid as plant adaptation to the potential environmental stresses. Vegetative indexes like plant height and peduncle length and in some cases the dry biomass accumulation are positively affected along with an increased R: S ratio, so we can conclude that these treatments helped the plant to adapt to and perform better in response to environmental situation by a more effective root system which has supported a better shoot growth.

We observed a range of $\mathrm{R}: \mathrm{S}$ ratio (3.5\% to $4.9 \% \mathrm{DW})$, which was lower than what was reported earlier by Niu and Rodriguez [21]. They reported R: S ratios between 7 to $8 \%$ by planting the plants in a lighter medium (Canadian sphagnum peat moss, perlite + wetting agent) which could induce more root proliferation than what we used (mixture of garden soil, leaf compost, and peat moss). Using a lighter medium can increase the recovery rate of fine roots, which hold a large share in Gazania. In our experiment, possibly the heavier applied medium caused losing part of extra fine roots and root hairs during the root isolation process for weighting. However, as this potential loss has affected all of treatments in a same manner, it cannot be considered as a source of variation in our study. Our longer experiment period (150 versus 90 days) could be another point explaining this difference. Decrease in $\mathrm{R}: \mathrm{S}$ ratio by age/size in herbaceous plants is well documented [22]. Nevertheless, more data on $\mathrm{R}: \mathrm{S}$ ratio of Gazania plant in different culture conditions may be needed to reach a final conclusion.

In the root, dry weight, and flower display time, we observed significant differences in response to applied citric acid concentrations. In malic acid, while there were no significant differences between applied concentrations, but in the root, fresh weight, and root dry weight, we see that only the higher concentration is considered significantly different from the control. When comparing with earlier reports, here we observe more similarity between responses of selected traits to organic acids. In some traits, the lower concentration gave good results that give us the idea of possible distinct patterns of response to concentration of applied organic acids. Therefore, we suggest testing both lower and higher concentrations of these organic acids to reach a better understanding in this regard.

SEM analysis proposes a controlling effect by shoot dry weight on $\mathrm{R}: \mathrm{S}$ ratio. On the other side, it suggests that root dry and fresh weights are positively affected by shoot biomass. This may seem contrasting and could be a matter 
of question. We can conclude that the observed controlling effect of shoot dry weight on $\mathrm{R}: \mathrm{S}$ ratio could result from decrease in $R: S$ ratio by increasing of plant size/age. This would be in accordance with a previous conclusion in a review of literature by Wilson regarding decrease in $\mathrm{R}: \mathrm{S}$ ratio of herbaceous plants with age/size, with the exception of being in root crops [22]. Observation of the dependence of the root dry and fresh weight on the shoot dry weight could be a representative of the dependence of root growth on allocated carbohydrates by shoot. Therefore, it would be natural to expect a larger root system supported by a larger shoot system.

\section{Conclusion}

Citric acid and malic acid possibly affected carbohydrate partitioning toward root allocation in our study. The stronger root system supported better shoot system in response. Considering the accumulated data regarding effects of citric acid and malic acid and the way they affect plants in relatively low concentrations and the consistency among plants from different families, a distinct pattern of regulative effects could be noted. The fact that they affect plant in low concentration along with inhibitory effect by higher concentrations of these organic acids, which is reported earlier, enables us to conclude that their carbohydrate content may not play an important role in creating the observed responses. As these are both environment-friendly and low cost agents, it seems promising to continue work to summarize the distinct effects of these organic acids on plants and to understand the mechanism by which they manifest their effects on plants.

In addition, we may draw attention to the use of structural equations modeling (SEM) in this kind of studies; as we can see here, it can help to uncover and visualize the key important points of interest out of the results in a concise manner. However, there are some differences visible between outputs of ANOVA and SEM that are due to the difference in algorithm of calculation. SEM analysis gives more weight to the correlation between variables than ANOVA. By putting both analyses together, we can obtain a more comprehensive output. To confirm the suggested path of effects and proposed model, further work in different conditions on the same plant would be of interest. Mitchell [23] recommended use of SEM as a powerful tool for applying path analysis to observational data sets in ecology and evolution, and here we can see a positive perspective for application of this modeling tool in plant studies, as well.

\section{Conflict of Interests}

The authors declare that there is no conflict of interests regarding the publication of this paper.

\section{References}

[1] S. Howis, N. P. Barker, and L. Mucina, "Globally grown, but poorly known: Species limits and biogeography of Gazania Gaertn. (Asteraceae) inferred from chloroplast and nuclear DNA sequence data," Taxon, vol. 58, no. 3, pp. 871-882, 2009.
[2] A. Vujošević, N. Lakić, D. Beatović, and S. Jelačić, "Influence of slow disintegrating fertilizer rates on quality of gazania (Gazania rigens L.) seedlings," Journal of Agricultural Sciences, vol. 52, pp. 121-130, 2007.

[3] D. R. Pittenger, D. A. Shaw, D. R. Hodel, and D. B. Holt, "Responses of landscape groundcovers to minimum irrigation," Journal of Environmental Horticulture, vol. 19, pp. 78-84, 2001.

[4] J. A. T. da Silva, "The cut flower: postharvest considerations," Journal of Biological Sciences, vol. 3, no. 4, pp. 406-442, 2003.

[5] D. A. Day and J. B. Hanson, "Pyruvate and malate transport and oxidation in corn mitochondria," Plant Physiology, vol. 59, no. 4, pp. 630-635, 1977.

[6] I. P. Ting, "Towards a model for malate accumulation in plant tissues," Plant Science Letters, vol. 21, no. 3, pp. 215-221, 1981.

[7] C. Osmond and G. G. Laties, "Compartmentation of malate in relation to ion absorption in beet," Plant Physiology, vol. 44, no. 7, 1969.

[8] J. Lopez-Bucio, M. F. Nieto-Jacobo, V. Ramírez-Rodríguez, and L. Herrera-Estrella, "Organic acid metabolism in plants: from adaptive physiology to transgenic varieties for cultivation in extreme soils," Plant Science, vol. 160, no. 1, pp. 1-13, 2000.

[9] B. Eidyan, E. Hadavi, and N. Moalemi, "Pre-harvest foliar application of iron sulfate and citric acid combined with urea fertigation affects growth and vase life of tuberose (Polianthes tuberosa L.) 'Por-Par,'” Horticulture Environment and Biotechnology, vol. 55, no. 1, pp. 9-13, 2014.

[10] N. Darandeh and E. Hadavi, "Effect of pre-harvest foliar application of citric acid and malic acid on chlorophyll content and post-harvest vase life of Lilium cv. Brunello," Frontiers in Plant Science: Crop Science and Horticulture, vol. 2, article 106, 2012.

[11] N. Jaafari and E. Hadavi, "Growth and essential oil yield of Basil (ocimum basilicum L.) as affected by foliar spray of citric acid and salicylic acid," Zeitschrift fur Arznei- und Gewurzplanzen, vol. 17, no. 2, pp. 80-83, 2012.

[12] N. Jafari and E. Hadavi, "Growth and essential oil yield of dill (Anethum graveolens) as affected by foliar sprays of citric acid and malic acid," Acta Horticulturae, vol. 955, pp. 287-290, 2012.

[13] Y. An, P. Zhou, Q. Xiao, and D. Shi, "Effects of foliar application of organic acids on alleviation of aluminum toxicity in alfalfa," Journal of Plant Nutrition and Soil Science, vol. 177, no. 3, pp. 421-430, 2014.

[14] W. El-Tohamy, H. El-Abagy, M. Badr, and N. Gruda, "Drought tolerance and water status of bean plants (phaseolus vulgaris 1.) as affected by citric acid application," Journal of Applied Botany and Food Quality, vol. 86, pp. 212-216, 2013.

[15] V. Maleki, M. R. Ardakani, F. Rejali, and A. A. Taherpour, "Physiological responses of sweet basil (Ocimum basilicum L.) to triple inoculation with azotobacter, azospirillum, glomus intraradices and foliar application of citric acid," Annals of Biological Research, vol. 4, pp. 62-71, 2013.

[16] M. Andrews, J. I. Sprent, J. A. Raven, and P. E. Eady, "Relationships between shoot to root ratio, growth and leaf soluble protein concentration of Pisum sativum, Phaseolus vulgaris and Triticum aestivum under different nutrient deficiencies," Plant, Cell and Environment, vol. 22, no. 8, pp. 949-958, 1999.

[17] M. Andrews, J. A. Raven, and J. I. Sprent, "Environmental effects on dry matter partitioning between shoot and root of crop plants: relations with growth and shoot protein concentration," Annals of Applied Biology, vol. 138, no. 1, pp. 57-68, 2001. 
[18] M. Andrews, J. A. Raven, P. J. Lea, and J. I. Sprent, "A role for shoot protein in shoot-root dry matter allocation in higher plants," Annals of Botany, vol. 97, no. 1, pp. 3-10, 2006.

[19] R. Hunt and A. O. Nicholls, "Stress and the coarse control of growth and root-shoot partitioning in herbaceous plants.," Oikos, vol. 47, no. 2, pp. 149-158, 1986.

[20] F. Lloret, C. Casanovas, and J. Peñuelas, "Seedling survival of Mediterranean shrubland species in relation to root:shoot ratio, seed size and water and nitrogen use," Functional Ecology, vol. 13, no. 2, pp. 210-216, 1999.

[21] G. Niu and D. S. Rodriguez, "Relative salt tolerance of selected herbaceous perennials and groundcovers," Scientia Horticulturae, vol. 110, no. 4, pp. 352-358, 2006.

[22] J. B. Wilson, "A review of evidence on the control of shoot: root ratio, in relation to models," Annals of Botany, vol. 61, no. 4, pp. 433-449, 1988.

[23] R. J. Mitchell, “Testing evolutionary and ecological hypotheses using path analysis and structural equation modelling," Functional Ecology, vol. 6, no. 2, pp. 123-129, 1992. 


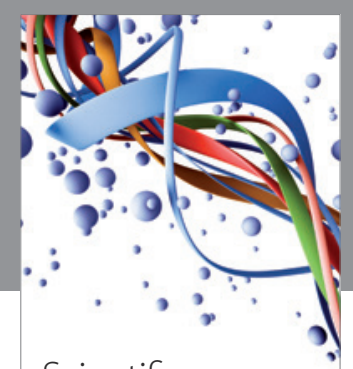

Scientifica
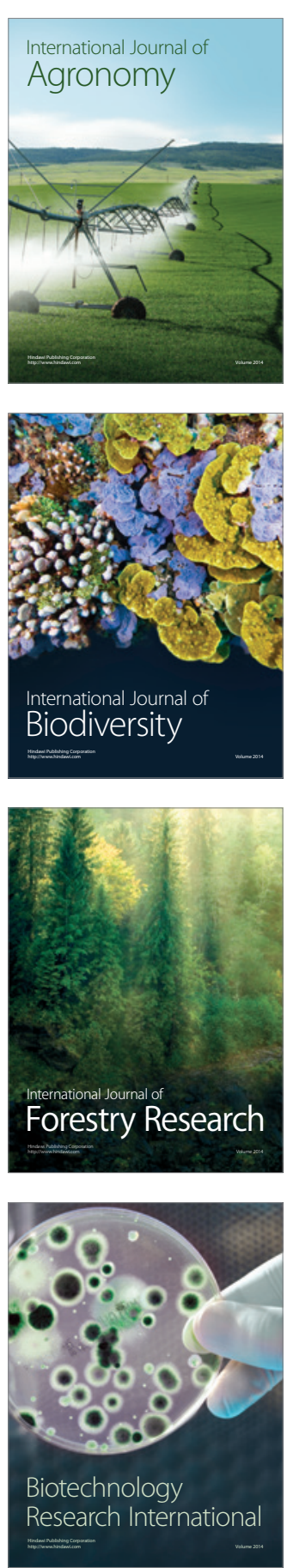
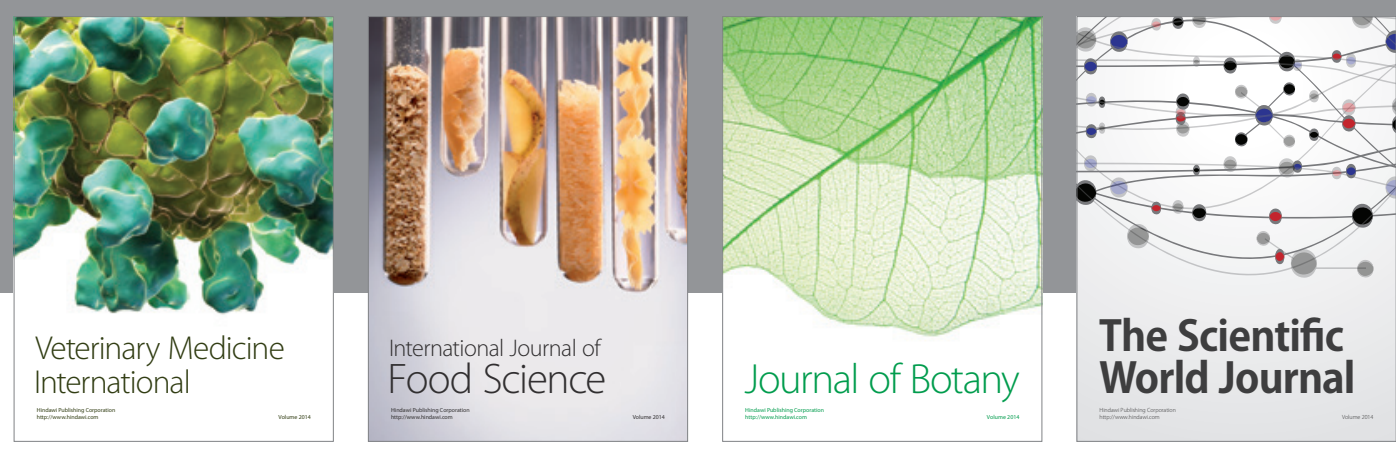

The Scientific World Journal
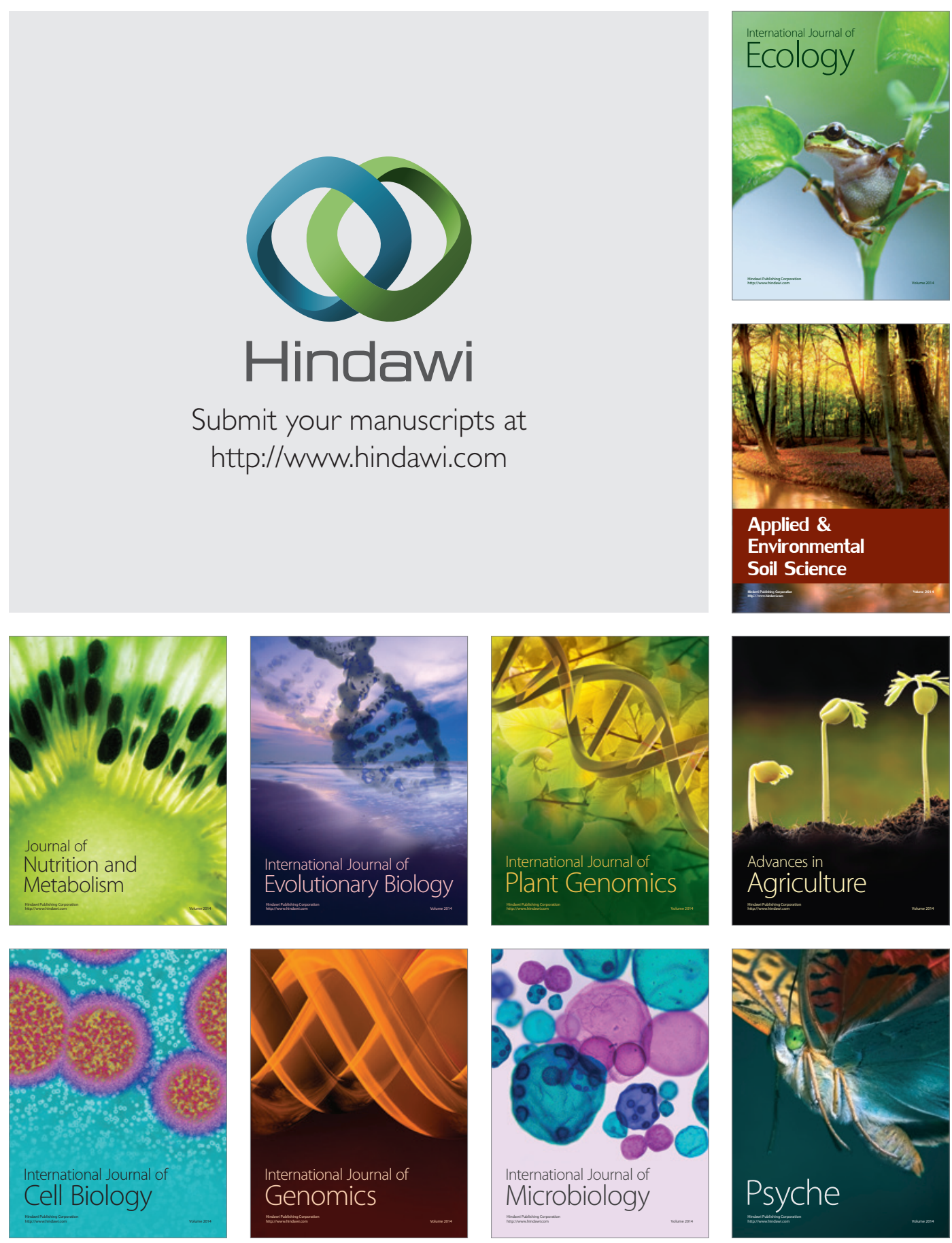